\title{
Is there need to augment the food safety knowledge, safe handling practices and purchasing behaviour among medical students
}

\author{
Parul Sharma $^{1, *}$, Kajal Srivastava ${ }^{2}$, A. Banerjee ${ }^{3}$, Vyas Shaili $^{4}$ \\ ${ }^{1,3}$ Profesor, ${ }^{2}$ Associate Professor, Dept. of Community Medicine, Dr. D.Y. Patil Medical College, Pune, Maharashtra, ${ }^{4}$ Associate \\ Professor, Himalayan Institute of Medical Science, Uttarakhand, India \\ *Corresponding Author: \\ Email: kajal.spm@gmail.com
}

\begin{abstract}
Introduction: Ascertaining food safety knowledge, attitude and practice of students have high importance because this eventually will lead to more food-conscious society and more healthy people. Only a handful of studies have been done to evaluate food safety practices among medical students.

Aim and Objectives: To assess knowledge, attitude and practices regarding food safety practices among medical students. ${ }^{2}$

To impart health education regarding correct food safety practices to the medical students.

Materials and Methods: A total of 100 students were covered after verbal consent. Information was collected on a pre-tested and pre-designed questionnaire on knowledge, safe handling and purchasing practices pertaining to safe food handling.

Results: Majority (59\%) had good knowledge on food safety practices, greater number had poor purchasing power behaviour and none scored good son safe handling practices score.

Conclusion: The target study highlighted that students with good knowledge scores was only 40 percent, majority [77 percent] had poor purchasing power scores whereas none of the students had good safe handling techniques knowledge.
\end{abstract}

Keywords: Food safety, Knowledge, Medical students.

\section{Introduction}

Food can be contaminated at any point of production and distribution. Major sources of food poisoning include pathogenic microorganisms, toxic animals and plants, chemical contamination, illegal additives and toxic industrial waste. ${ }^{1}$ According to the World Health Organization, foodborne and waterborne diarrheal diseases kill an estimated 2 million people annually, mostly children and particularly in developing countries. ${ }^{3}$ Serious foodborne disease outbreaks have occurred on every continent in the past decade, due to inadequate food safety laws, weak regulatory systems, and lack of education for food handlers and consumers. ${ }^{3}$ About 2 million deaths due to diarrhoea in developing countries are related to contaminated food according to WHO. ${ }^{4}$ In developing countries, 1.8 million children under the age of five die from diarrheal illness each year out of which $70 \%$ are due to infections with food borne pathogens. ${ }^{5}$ The risk of foodborne diseases is most severe in low and middle income countries, linked to preparing food with unsafe water; poor hygiene and inadequate conditions in food production and storage; lower levels of literacy and education; and insufficient food safety legislation or implementation of such legislation. ${ }^{6}$ This survey evaluated the knowledge, purchasing behaviour and safe handling practices among medical students.

\section{Aim and Objectives}

1. To assess knowledge, attitude and practices regarding food safety practices among medical students.
2. To impart health education regarding correct food safety practices to the medical students.

\section{Materials and Methods}

Institutional based cross-sectional study.

Study Subjects: 4 th and $6^{\text {th }}$ semester MBBS students Study Period: $1^{\text {st }}$ April to $31^{\text {st }}$ May'16

Sampling Technique: convenience sampling.

Sample Size: 100 student.

Study Tool: The questionnaire consisted of three sections i.e. Section A, B and C. Section A and B were pre-designed and pre-tested and Section $\mathrm{C}$ was taken from a study by Nizar Issa Alrabadi et al in Jordan $(2013)^{7}$ Section. A consisted questions on sociodemographic variables and Section B consisted of 25 questions on knowledge, Section $\mathrm{C}$ consisted questions on Attitude and practice regarding food safety i.e. 9 questions on purchasing behavior means checking of printed advice on product, expiry, and presence of preservatives, storage and preparation instructions and 12 questions on safe handling. Each correct answer in knowledge section was marked as 1 and each incorrect answer was marked as 0 . Therefore the maximum score for knowledge was 25 and minimum score was 0 .For Purchasing behavior; each of the nine questions were marked on a Likert scale from always to never. Scoring was done as always (score 5), frequently (score 4), sometimes (score 3), rarely (score 2) and never (Score 1 ). So the maximum sore $=45$ and minimum score $=9$. For safe handling the scoring was done on Likert scale ranging from always (5) to never (1) except questions 7 , 9 and 12 which were negatively scored. The composite knowledge score was categorized as poor $(<8)$, fair $(8-$ 
18) to good $(>20)$. Purchasing behavior was scored as poor (<9), fair (9-30) and good (>30). Safe handling was categorized as poor $(<12)$, fair $(12-45)$ and good $(>45)$.

\section{Results}

In the study the knowledge regarding food safety was found to be fair among 59\% students (95\% CI; 0.491 to 0.6832 ) followed by good knowledge score in $40 \%$ students (95\% CI; 0.3075 to 0.4982 ). In our study the purchasing behaviour score was found to be poor in majority $(77 \%)$ of the students $(95 \% \mathrm{CI} ; 0.6800$ to $0.8446)$ and the score was fair in $22 \%$ study subjects (95\% CI; 0.1470 to 0.3090$)$. In the present study none of the students had good safe handling practices whereas $86 \%$ had poor safe handling practice score (95\% I0.7814 to 0.9180) followed by $14 \%$ students with fair safe handling scores (95\% CI (0.820 to $0.2186)$.

\section{Chart 1: Methodology flowchart}

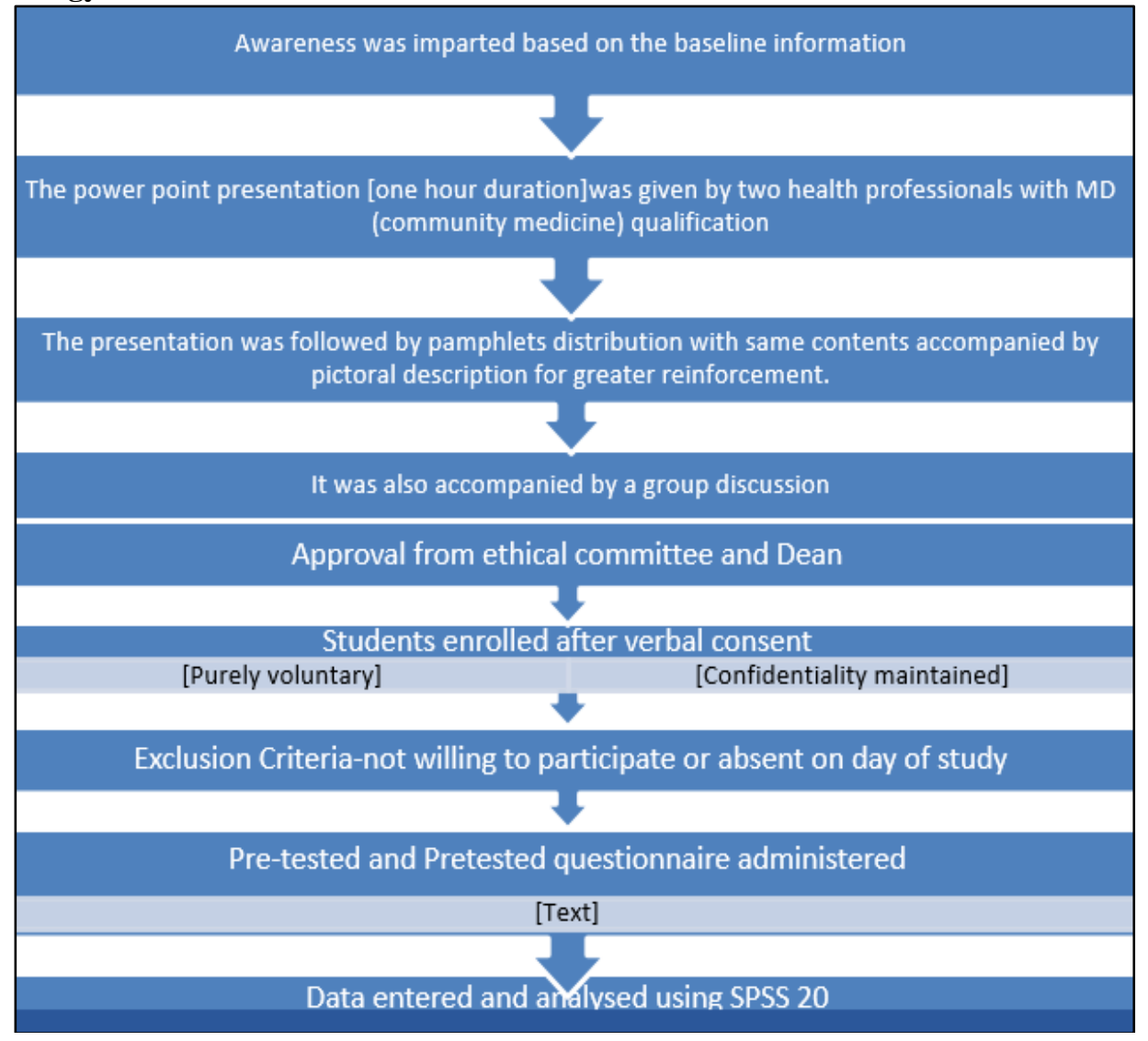

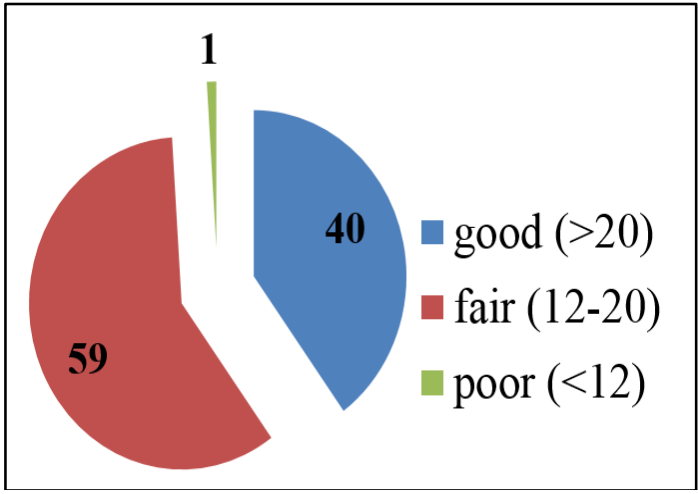

Fig. 1: Frequency of knowledge Score

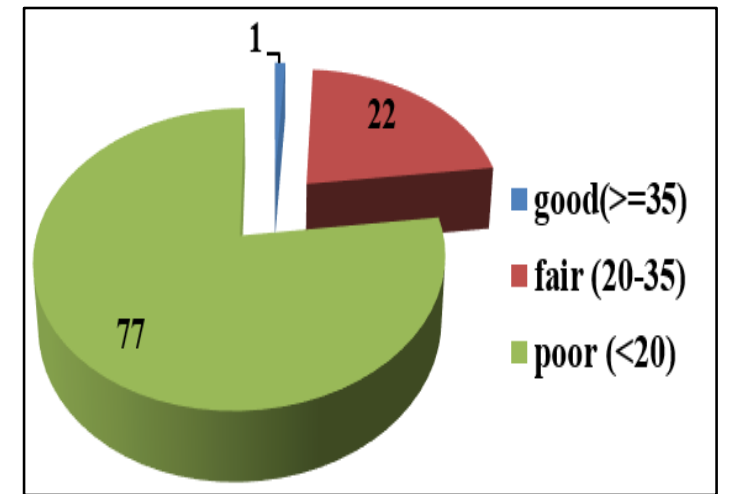

Fig. 2: Purchasing Behaviour Score 


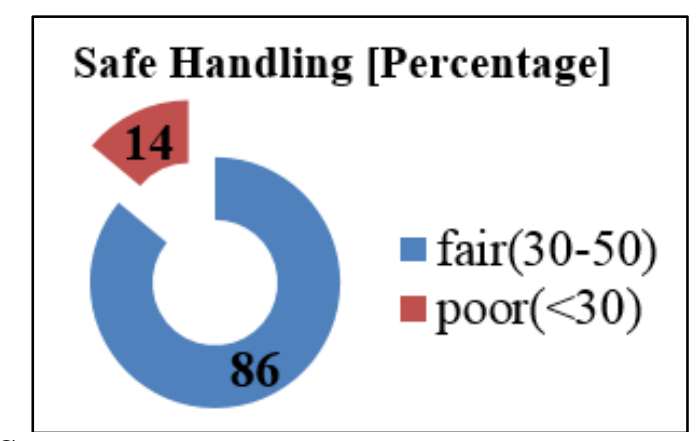

Fig. 3: Safe Handling Practice Score

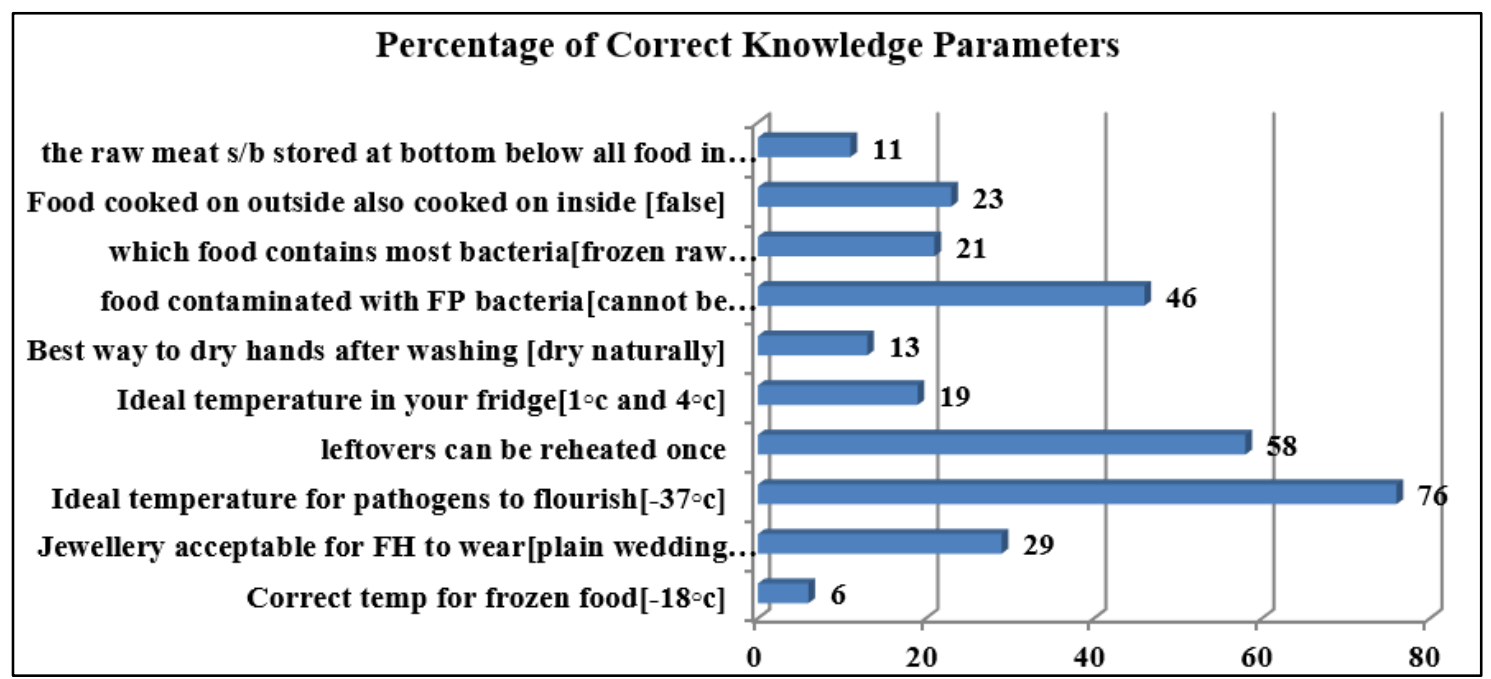

Fig. 4: Correct Knowledge Parameters

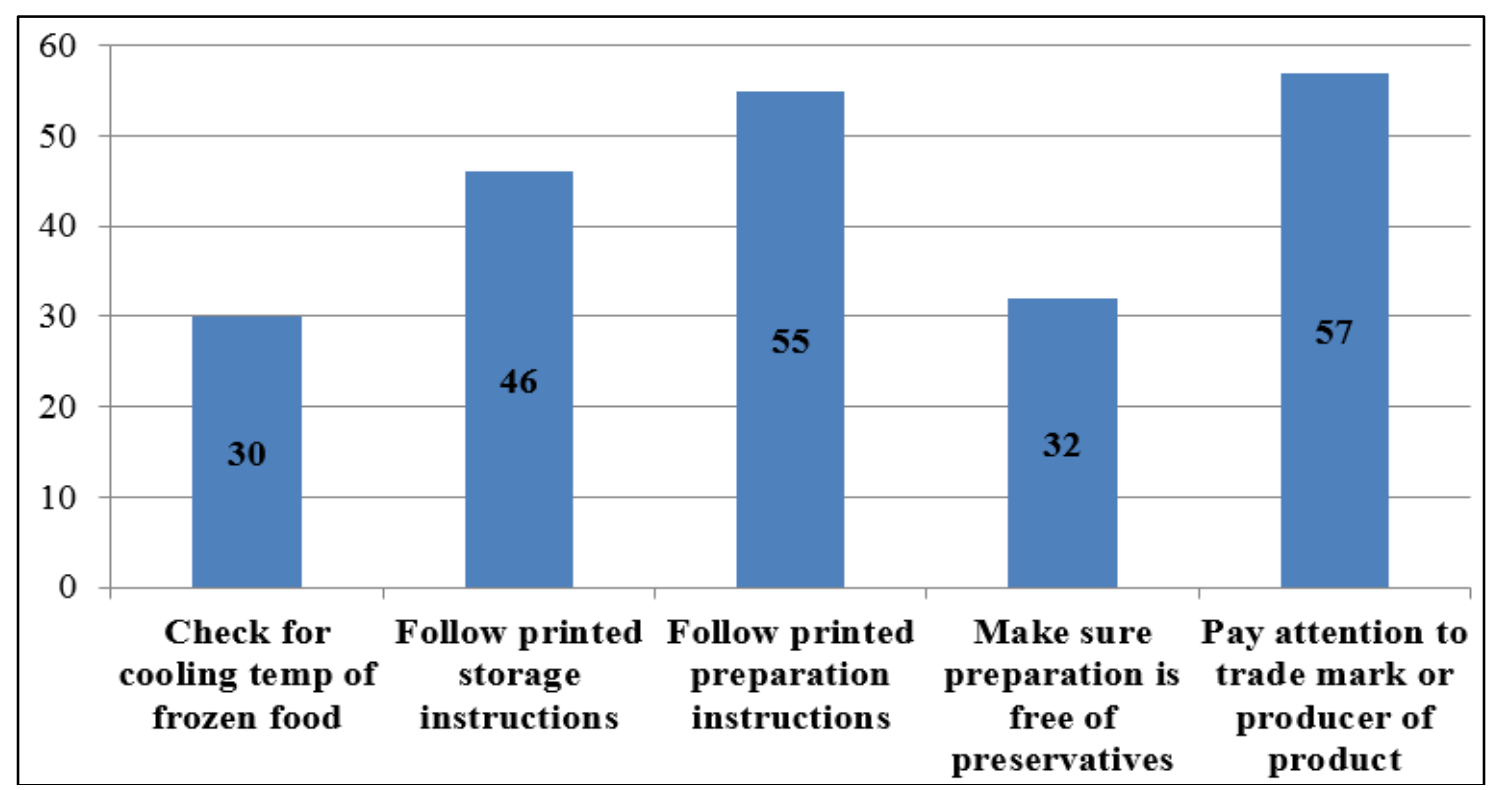

Fig. 5: Most appropriate purchasing behaviour options 


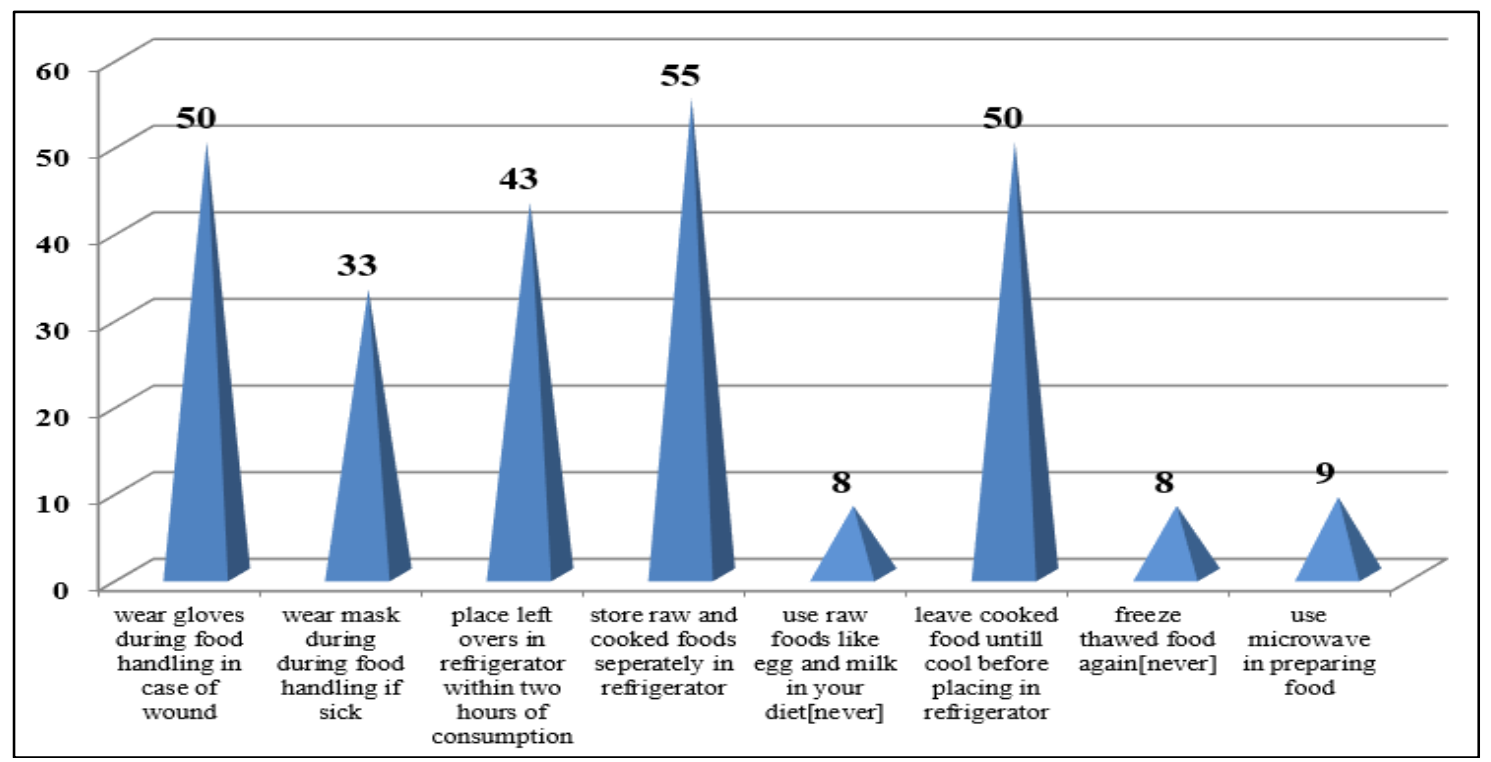

Fig. 6: Most appropriate safe handling options (Percentage)

\section{Discussion}

In the study the knowledge regarding food safety was found to be fair among 59\% students (95\% CI;0.491 to 0.6832) followed by good knowledge score in $40 \%$ students $(95 \% \mathrm{CI} ; 0.3075$ to 0.4982$)$. In contrast to this a high level of food safety knowledge was observed among the participants (85.06\%) according to a study by Stratev D among veterinary medicine students at Trakia University, Bulgaria $(2017)^{8}$ Similar to our study, majority of respondents $(42.0 \%)$ had a high knowledge level according to a study among secondary school students in Beijing, China by Yinchu Cheng et al. ${ }^{9}$ The purchasing behaviour score was found to be poor in majority $(77 \%)$ of the students (95\% CI; 0.6800 to 0.8446 ) and the score was fair in $22 \%$ study subjects $(95 \% \mathrm{CI} ; 0.1470$ to 0.3090$)$. In contrast to this it was found that the knowledge of purchasing behaviour $(14.43 \pm 2.56)$ of food safety $(20.82 \pm 4.20)$ of the consumers living in Turkey was higher compared to those living in Kazakhstan ${ }^{10}$ $(11.84 \pm 2.92,14.74 \pm 3.86$ respectively). None of the students had good safe handling practices whereas $86 \%$ had poor safe handling practice score (95\% I0.7814 to 0.9180 ) followed by $14 \%$ students with fair safe handling scores (95\% CI (0.820 to 0.2186$)$. In contrast to these findings Andrej Ovca et $\mathrm{a}^{11}$ found in his study that the respondents with respect to knowledge regarding safe food handling practices, scored an average of 12.5 (SD 1/4 2.5), which represents a correctness rate of $65.8 \%$ (Solvenia, 2014). Similarly, Stratev $\mathrm{D}$ et $\mathrm{al}^{8}$ in his study among veterinary medicine students at Trakia University, Bulgaria found that the practice of food safety was above average $(65.28 \%)$.

The percentages for correct responses for individual questions for knowledge were poor very few (6\%) knew about correct temperature for frozen food $\left(-18^{\circ} \mathrm{C}\right)$,
Only $19 \%$ were aware that hands should be dried naturally after washing (13\%). One-fifth knew that frozen raw chicken contains more bacteria and the ideal temperature in your fridge is $1^{\circ}$ to $4^{\circ} \mathrm{C}$. More than half $(58 \%)$ said that the leftovers can be heated once whereas majority $(76 \%)$ knew that the ideal temperature for pathogen to florish is- $37^{\circ} \mathrm{C}$. In the target population more than half the respondants $(57 \%)$ pay attention to trade mark or producer of product and approx. half (55\%) follow printed preparation instructions. In contrast to this in another study by Nizar Issa Alrabadi et al in Jordan (2013) only 19\% pay attention to trade mark or producer of product and very few $(11 \%)$ follow the printed preparation instructions. Only one-third check for cooling temperature of frozen food and make sure that the preparation is free of preservatives.Similarly in Only 7\% check for cooling temperature of frozen food and make sure that the preparation is free of preservatives according to study by Nizar Issa Alrabadi et $\mathrm{al}^{7}$ in Jordan (2013). In the present study approx. Half (43\%) placed left overs in refrigerator within two hours of consumption, only $8 \%$ students never used raw foods like egg and milk in diet and had never freeze thawed food again. Only, half the population wore gloves during food handling in case of wound. Similarly, according to a study by Nizar Issa Alrabadi et al in Jordan (2013) ${ }^{7}$ found out in his study that more than half of the respondents always or frequently place leftover foods in the refrigerator in no later than two hours of consumption $24 \%$ of respondents rarely use raw foods such as eggs, meat and milk in food and 58\% never do so. 63\% rarely or never freeze thawed food again. 


\section{Conclusion}

The target study highlighted that students with good knowledge scores was only 40 percent, majority [77 percent] had poor purchasing power scores whereas none of the students had good safe handling techniques knowledge.

\section{Recommendation}

More emphasis should be given to teaching the students regarding knowledge about correct purchasing power and safe handling techniques also along with imparting them knowledge regarding food safety while covering curriculum on Nutrition.

\section{Limitation of the Study}

This study was done on MBBS students who are supposed to have better knowledge so restricted to medical college only while it can be extended to community as well.

\section{Relevance of the Study}

Food safety is a global public health concern. The problem of food safety not only affects human health but also the economy. Among the several courses taught to medical Students nutrition and food safety. This topic has been taught for several years. However, few studies have been carried out to evaluate food safety knowledge, attitudes and practices among medical and paramedical students. This survey evaluated the knowledge, purchasing power and safe handling practices among medical students.

\section{Acknowledgement}

Thankful to all MBBS students who participated in study.

\section{References}

1. Lam H-M, Remais J, Fung M-C, Xu L, Sun SS-M. Food supply and food safety issues in China. The Lancet. 2013;381(9882):2044-53.

2. World Health Organization. Fact sheet no: Food safety. Cited 2016; 399(8)1-6. Available from: http://www.who.int/mediacentre/factsheets/fs399/en/

3. Abdullahi A, Hassan A, Kadarman N, Saleh A, Shu'aibu YB, Lua PL. Food safety knowledge, attitude, and practice toward compliance with abattoir laws among the abattoir workers in Malaysia. IJGM. 2016;1;79.

4. World Health Organization. Fact sheet no 399: Food safety [Internet]. 2015 [cited 2016 Sep 8]. pp. 1-6. Availablefrom: http://www.who.int/mediacentre/factsheet s/fs399/en/

5. https://www.eolss.net/sample-chapters/C10/E5-08-0200.pdf[last assessed on 25/05/2018]

6. http://www.who.int/news-room/detail/03-12-2015-who-sfirst-ever-global-estimates-of-foodborne-diseases-findchildren-under-5-account-for-almost-one-third-of-deaths

7. Nizar Issa Alrabadi, Motasem AL-Massad and Omar Alboqai. Food Safety: A Study of Jordanian Consumer's Knowledge and Practices. World Applied Sciences Journal. 2013;22(1):35-40.
8. Stratev D, Odeyemi OA, Pavlov A, Kyuchukova R, Fatehi F, Bamidele FA Food safety knowledge and hygiene practices among veterinary medicine students at Trakia University, Bulgaria. J Infect Public Health. 2017;10(6):778-782.

9. Yinchu Cheng, Yang Zhang, Jun Ma, Siyan Zhan. Food safety knowledge, attitude and self-reported practice of secondary school students in Beijing, China: A crosssectional study.

10. Nevin Sanlier, Ayhan Dağdeviren, Bülent Çelik, Saniye Bilici and Aktolkin Abubakirova. Determining the knowledge of food safety and purchasing behavior of the consumers living in Turkey and Kazakhstan. African Journal of Microbiology Research. 2011;5(18):27242732.

11. Ovca, Andrej \& Jevšnik, Mojca \& Raspor, Peter. (2014). Food safety awareness, knowledge and practices among students in Slovenia. Food Control. 2014;42:144-151. 10.1016/j.foodcont.2014.01.036 